\title{
The cleft ion fountain: a two-dimensional kinetic model
}

\author{
Article \\ Published Version
}

Horwitz, J. L. and Lockwood, M. (1985) The cleft ion fountain: a two-dimensional kinetic model. Journal of Geophysical Research, 90 (A10). pp. 9749-9762. ISSN 0148-0227 doi: https://doi.org/10.1029/JA090iA10p09749 Available at https://centaur.reading.ac.uk/38914/

It is advisable to refer to the publisher's version if you intend to cite from the work. See Guidance on citing.

Published version at: http://dx.doi.org/10.1029/JA090iA10p09749

To link to this article DOI: http://dx.doi.org/10.1029/JA090iA10p09749

Publisher: American Geophysical Union

All outputs in CentAUR are protected by Intellectual Property Rights law, including copyright law. Copyright and IPR is retained by the creators or other copyright holders. Terms and conditions for use of this material are defined in the End User Agreement.

\section{www.reading.ac.uk/centaur}

\section{CentAUR}

Central Archive at the University of Reading

Reading's research outputs online 


\title{
The Cleft Ion Fountain: A Two-Dimensional Kinetic Model
}

\author{
J. L. HORWTTZ \\ Department of Physics, The University of Alabama in Huntsville \\ M. LOCKWOOD ${ }^{1}$ \\ Space Science Laboratory, NASA Marshall Space Flight Center, Huntsville, Alabama
}

\begin{abstract}
The transport of ionospheric ions from a source in the polar cleft ionosphere through the polar magnetosphere is investigated using a two-dimensional, kinetic, trajectory-based code. The transport model includes the effects of gravitation, longitudinal magnetic gradient force, convection electric fields, and parallel electric fields. Individual ion trajectories as well as distribution functions and resulting bulk parameters of density, parallel average energy, and parallel flux for a presumed cleft ionosphere source distribution are presented for various conditions to illustrate parametrically the dependences on source energies, convection electric field strengths, ion masses, and parallel electric field strengths. The essential features of the model are consistent with the concept of a cleft-based ion fountain supplying ionospheric ions to the polar magnetosphere, and the resulting plasma distributions and parameters are in general agreement with recent lowenergy ion measurements from the DE 1 satellite.
\end{abstract}

\section{INTRODUCTION}

In recent years a principal focus of magnetospheric research has been on the ionosphere as a source of plasmas in the magnetosphere [e.g., Horwitz, 1982]. Currently, there is particularly intense study on the varieties of upflowing ion distributions observed with Dynamics Explorer (DE) as well as with other spacecraft. These new observations are being used to investigate conic and beam distributions in the auroral ionosphere [e.g., Yau et al., 1984; J. D. Winningham and J. L. Burch, unpublished manuscript, 1984], the occurrence of ions over the polar cap [Shelley et al., 1982; Waite et al., 1985] and their possible polar cusp or cleft ionospheric source region [e.g., Lockwood et al., 1985; Moore et al., 1984; Peterson, 1985], and the mass and energy separation of these upflowing ions due to convection and energy/mass-dependent parallel motion [e.g., Moore et al., 1985; Lockwood et al., this issue; Gurgiolo and Burch, 1982].

At the same time, observations within the high-altitude magnetosphere itself have demonstrated that ions of ionospheric origin are an important component of the energetic plasma populations in the ring current [e.g., Lennartson et al., 1979, 1981; Balsiger et al., 1980; Lundin et al., 1980], plasma sheet [e.g., Peterson et al., 1981; Sharp et al., 1981], and plasma lobes and mantle [Sharp et al., 1981; Lundin et al., 1982], and of course, plasma of ionospheric origin dominates the very low-energy plasma seen in these regions [e.g., Horwitz et al., 1982; Nagai et al., 1983; Sharp et al., 1981] and the plasmasphere [e.g., Horwitz et al., 1984].

It is thus important and timely to develop models to investigate the transport of the upflowing ionospheric ions through the polar magnetosphere and into the high-

\footnotetext{
1 On sabbatical leave from Rutherford Appleton Laboratory Chilton, Didcot, England.

Copyright 1985 by the American Geophysical Union.

Paper number 5A8487.

0148-0227/85/005A-8487\$05.00
}

altitude tail and equatorial magnetosphere. Recently, Horwitz [1984] considered a simple two-dimensional magnetospheric model and obtained ion trajectories in the polar and tail magnetosphere for a range of injection masses, energies, pitch angles, and locations, including the effects of the convection electric fields, gravitation, and the magnetic gradient force. These calculations were used to illustrate the mass and energy separation of ions injected at the polar cusp ionsophere that has been observed in DE 1 low-energy ion measurements poleward of the cusp/cleft [Moore et al., 1985] and to suggest some interesting further consequences of such transport. For example, there were initial indications that the low-energy $\mathrm{O}^{+}$from the polar cleft ionsopheric injection site could be fed into the nightside auroral acceleration region near $\sim 1 R_{E}$ altitude [e.g., Ghielmetti et al., 1978; Gorney et al., 1981]. Lockwood et al. [1985] have suggested that through such transport, at least part of the energetic $\mathrm{O}^{+}$observed to be streaming out of the auroral acceleration region may have started out in the polar cleft ionosphere. Horwitz [1984] also illustrated how energetic ions injected from the polar cleft ionosphere [e.g., Peterson, 1985], in undergoing the mass and energy separation during transport into the distant tail magnetosphere, can result in preferential trapping of $\mathrm{O}^{+}$relative to $\mathrm{H}^{+}$and $\mathrm{He}^{+}$into the closed field line region of the magnetotail plasma sheet, thereby leading to a fractional dominance of energetic $\mathrm{O}^{+}$over the light ions in the plasma sheet larger than that present in the ionospheric source composition, in the case where all ions come from the polar cleft ionosphere.

Horwitz [1984] also showed that if gravity dominates the motion, characteristic ion trajectories can become apparent at low-convection electric fields with certain ranges of ion injection parameters. Two classes of such ion trajectories for low-energy $\mathrm{O}^{+}$injected from the polar cleft ionosphere were noted: (1) "parabolic" trajectories, in which heavy ions injected nearly along the magnetic field lines rise and then fall into the polar cap atmosphere, and (2) "hopping" trajectories, in which heavy ions injected at nearly perpendicular pitch angles in the polar cleft ionosphere reflect between the gravitational stopping location and the magnetic mirror point as they convect at low to 

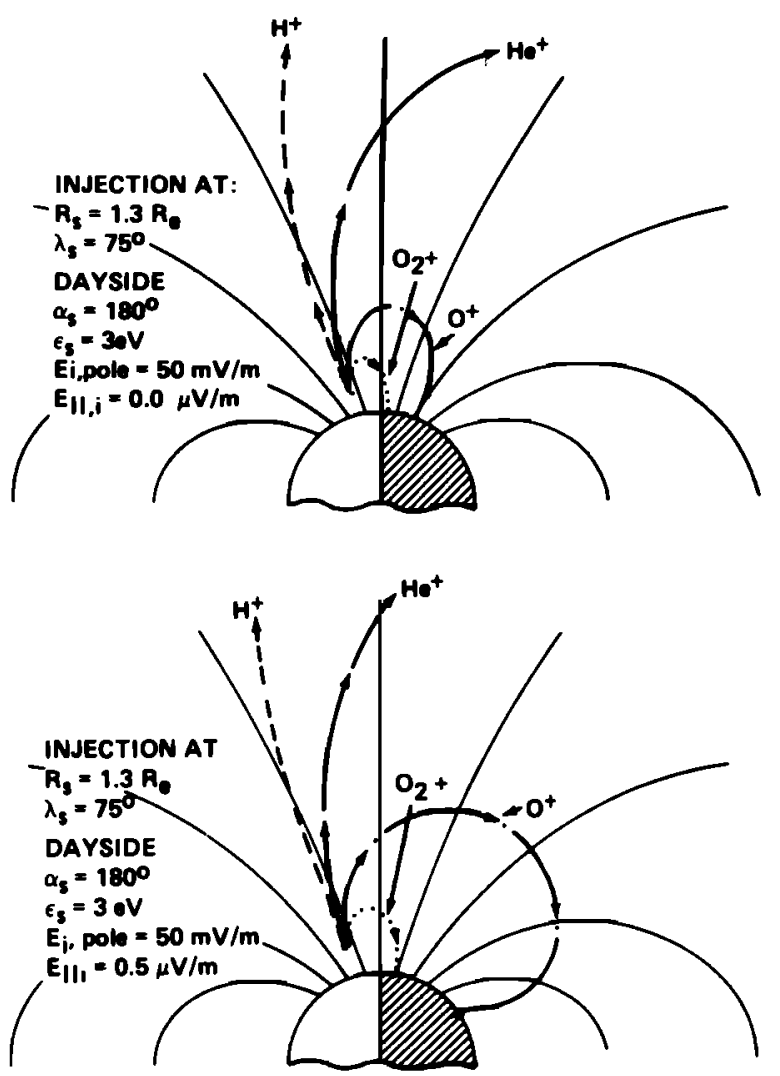

Fig. 1. Trajectories of four ion species injected at the cleft ion fountain for two values of the ionospheric parallel electric field. For this case, only the $\mathrm{O}^{+}$trajectory is substantially affected by the difference in $E_{\|, i}$ between the top and bottom panels. The representative magnetic field lines displayed are for foot point latitudes spaced by $10^{\circ}$ starting on the dayside at $\lambda=50^{\circ}$.

intermediate altitudes across the polar cap. Ion trajectories were also computed for the possible case of injection from the nightside auroral lonosphere during periods when the interplanetary magnetic field has a northward component and convection in the central polar cap can be sunward [e.g., Maezawa, 1976; Horwitz and Akasofu, 1979; Burke et al., 1979]. Such conditions could lead to a pronounced "spray" of ions, in which the injected ions would appear in the dayside or nightside magnetosphere depending mainly on the ion mass and energy and the magnitude of the dusk-dawn convection electric field.

The purpose of this paper is to investigate further the transport of such ions on the basis of the framework introduced by Horwitz [1984]. In the present work we include a distribution of small parallel electric fields to simulate approximately the effects of an ambipolar type of parallel electric field on the ion transport. Further, we calculate distribution functions and the resulting spatial distribution in the polar magnetosphere of selected bulk plasma parameters arising from source distributions identified with the polar cleft ionospheric upflowing ions [Moore et al., 1984]. These are displayed as contour maps of these bulk parameters for various conditions to illustrate several interesting effects of varying source distributions, convection and parallel electric field strengths, and ion masses on the spatial distributions of the plasma in the polar magnetosphere.

\section{Calculation TeChNiQues and AsSumptions}

The calculation of ion trajectories in this paper is essentially as described by Horwitz [1984] except that we further include a model distribution of parallel electric fields (see below). As in the work of Horwitz [1984], these are two-dimensional trajectories appropriate to plasma convection in the noon-midnight meridian. The magnetospheric magnetic field model used here is again that suggested by Luhmann and Friesen [1979], which consists of a dipole and a thin current sheet (with dawnto-dusk current flow), located at the magnetic equator. This simple magnetic field model reproduces remarkably well such features as the polar cusp and the basic tail geometry. The only transverse velocity considered in this paper is the convection velocity, $v_{\perp}=\mathrm{E} \times \mathrm{B} / B^{2}$, the gradient and curvature velocities being totally unimportant for the energies of interest here. The spatial electric field distribution is obtained by specifying the dawn-dusk electric field strength at $300-\mathrm{km}$ altitude at the ionospheric pole and then mapping the electric field as $B^{1 / 2}$ elsewhere as an approximation to the convention of assuming equipotential electric field lines. This approximation is equal to within $1-2 \%$ of the exact mapping factors for a dipole magnetic field for the latitude and geocentric distance ranges $\left(<5 R_{E}\right.$ ) considered for the polar magnetosphere studied here and is certainly within the range of other uncertainties involved (associated with magnetic field geometry, assumption of equipotential field lines, etc.) for the tail $\left(\sim 25 R_{E}\right)$ considerations that we envision later, where no analytic mapping factor is available for even the simple magnetic field model used here. The instantaneous parallel velocity is obtained by integrating the parallel force equation, which for this report includes the parallel magnetic gradient force, gravitation, and a parallel electric field (see below), and assuming conservation of the first adiabatic invarient, along the computed ion trajectory, starting from initial ion parameters of ion mass, energy, pitch angle, and location. Integrating the parallel and transverse velocities with time yields the ion trajectory paths in space.

For this report we will simulate the effects of parallel electric fields on the ion trajectories by specifying $E_{\|}$at the ionosphere, as with the convection field, and allowing the parallel electric field to have an inverse square dependence on geocentric distance as is the case with the gravitational field. Thus we assume

$$
E_{\|}(r)=E_{\|, i}\left(\frac{R_{0}}{r}\right)^{2}(+\widehat{\mathrm{g}} \cdot \widehat{\mathrm{b}})
$$

where $g$ and $b$ are the unit vectors in the directions of the gravitational and magnetic fields and $E_{\|, i}$ is the specified value at $R_{0}$ in the ionosphere (i.e., $300-\mathrm{km}$ altitude). The plausibility argument for taking the form for the parallel electric field given in (1) can be seen by noting that in an ionosphere in hydrostatic equilibrium, to maintain quasineutrality in the presence of gravity and pressure gradient forces between the ions and light electrons, an ambipolar parallel electric field directed upward is required:

$$
E_{\| h s^{\prime}}=\frac{\left\langle M_{i}\right\rangle}{2 e} g(+\widehat{\mathrm{g}} \cdot \widehat{\mathrm{b}})
$$




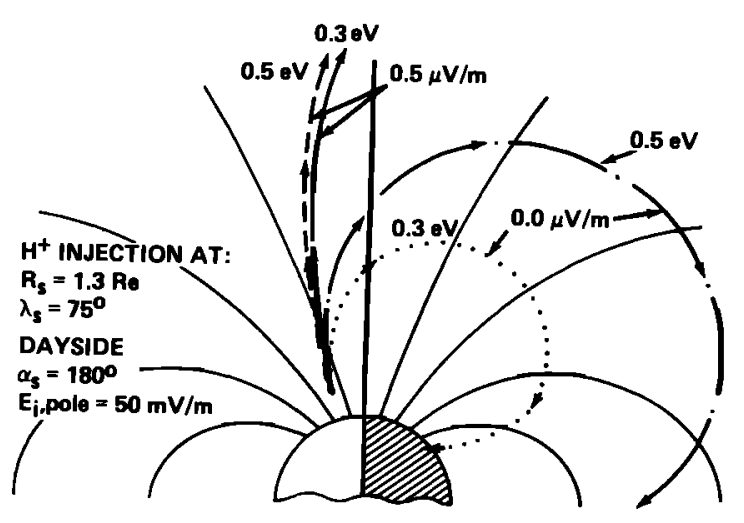

Fig. 2. Trajectories of $\mathrm{H}^{+}$with very low source energies for two ionospheric parallel electric fields. The $E_{\|, j}=0.5 \mu \mathrm{V} \mathrm{m}-1$ accelerates the $\mathrm{H}^{+}$upward and confines these ions to magnetic field lines near their source.

where $\left\langle M_{i}\right\rangle$ is the weighted ion mass and $e$ is the electronic charge. This is for the simplest case of equal and uniform ion and electron temperatures. If the weighted ion mass is further assumed constant, then the gravitational $1 / r^{2}$ dependence is also appropriate to the ambipolar electric field. Of course, it is expected that in the real polar ionosphere/magnetosphere, $E_{\|}$will vary with both latitude and altitude, owing to the obvious departures from the hydrostatic case, spatial variations in $\left\langle M_{i}\right\rangle, T_{i}, T_{e}$, and the effects of auroral particles and the polar rain. However, at this stage. it is difficult and beyond the scope of the present report to include these effects self-consistently in such a two-dimensional kinetic model of the transport. Instead, our philosophy in this report is to employ the simple and somewhat plausible form of (1) to study parametrically the ion trajectories and distributions for different values of $E \|_{i,}$. We note that the basic, largescale electric potential dependence seen in the one-dimensional study by Barakat and Schunk [1983] is roughly in accord with the potential which would result from (1). However, as will be shown in this report and the companion paper by Lockwood et al. [this issue], it appears that the two-dimensional transport from a narrow cleft source of heated ionospheric ions embodies the most important effects that can be observed in the DE 1 low-energy ion data, and hence our model makes a major new contribution even though the parallel electric field is not included self-consistently here. Indeed, there are some indications that the parallel electric field effects are small and secondary to these two-dimensional effects. For example, Lockwood et al. [this issue] show for one event that the estimated $E_{\|, i}$ is $\sim 0.1 \mu \mathrm{V} \mathrm{m}^{-1}$, corresponding to a total potential drop (below about $3 R_{E}$ or so in geocentric distance) of just $0.6 \mathrm{~V}$. Also, the $\mathrm{H}^{+}$flow energies of Nagai et al. [1984] are of the order of 2-4 eV at $\sim 4 R_{E}$ geocentric distance, which might indicate a potential drop of only $\sim 3 \mathrm{~V}$ below this location. These indicated electric fields and potential drops are within the ranges used in this report and are small enough to suggest that they do not dominate the transport to the extent of invalidating our approach. It should be noted, however, that these potential drop estimates are smaller than those potential drops estimated from photoelectron measuremenț by
Winningham and Gurgiolo [1982]. Possibly, these discrepancies can be reconciled if these large potential drops occur at high altitudes, above the $\leqslant 5 R_{E}$ region considered in the results presented here.

A chief focus of this paper is to illustrate the plasma distributions in the polar magnetosphere resulting from ion injection in the polar cleft ionosphere. The form for the initial ion distribution functions in the polar cleft ionosphere is here taken to be the upgoing half of a biMaxwellian (i.e., for the northem hemisphere):

$$
\begin{array}{rlrl}
f_{s}\left(v_{\perp}, v_{\|}\right)= & 2 n_{s}(m / 2 \pi k)^{3 / 2}\left(1 / T_{\perp s} T_{\|_{s}} 1 / 2\right) & \\
& \cdot \exp \left(-m v_{\perp}^{2} / 2 k T_{\perp s}-m v_{\|}^{2} / 2 k T_{\|}\right) & & v_{\|}<0 \\
f_{s}\left(v_{\perp}, v_{\|}\right)=0 & & v_{\|}>0
\end{array}
$$

or, in terms of the kinetic energy $e$ and pitch angle $\alpha$,

$$
\begin{aligned}
f_{s}(\epsilon, \alpha)= & 2 n_{s}\left(\frac{m}{2 \pi k}\right)^{3 / 2}\left(\frac{1}{T_{\perp s} T_{\| s} 1 / 2}\right) \cdot \exp \left\{\frac{\epsilon \sin ^{2} \alpha}{k T_{\perp s}}\right. \\
& \left.-\frac{\epsilon \cos ^{2} \alpha}{k T_{\|_{s}}}\right\} \quad \alpha>90^{\circ} \\
f_{s}(\epsilon, \alpha)= & 0
\end{aligned}
$$

where $k T_{\perp_{s}}$ and $k T_{\| s}$ are the initial perpendicular and parallel thermal energies, $n_{s}$ is the source density, and $m$ is the particle mass. In this report we will be considering various perpendicular and parallel thermal energies for our parametric illustrations of the effects on the resulting distributions in the polar magnetosphere.

We take these types of distributions to represent the "source" distributions at specified altitudes and ranges of latitudes, which can be varied. For the calculations in this report, we have taken the geocentric distance of injection to be $1.4 R_{E}$ and the latitudinal range to be either $70^{\circ}-73^{\circ}$ or $70^{\circ}-80^{\circ}$ on the dayside. This altitude is consistent generally with the source altitudes of Lockwood et al. [1985], as is the $70^{\circ}-73^{\circ}$ latitude range; the source latitude range of $70^{\circ}-80^{\circ}$ is somewhat broader than is usually indicated in the DE data at these altitudes, but it is chosen to allow use of a somewhat coarser (and thus less time consuming) spatial grid resolution in those calculations and contour plots of bulk parameters yet still illustrate the important effects of a relatively narrow cleft fountain.

The evaluation of the distribution functions in the magnetosphere regions is based on Liouville's theorem and the ion trajectory code. To calculate the distribution function at a given location $r$ in the magnetosphere, we specify an array of energies and pitch angles as $\epsilon_{i}, \alpha_{j}$ with $i=1$ to $N_{\epsilon}$ and $j=1$ to $N_{\alpha}$ that defines the phase space in which we wish to determine the distribution function $f\left(\mathbf{r}, \epsilon_{i}, \alpha_{j}\right)$. For each $\epsilon_{i}, \alpha_{j}$ at this location $\mathrm{r}$, we integrate the ion trajectory backward in time. If the trajectory never intersects the source location in the specified altitude and latitude range, then the distribution function for that energy and pitch angle at $r$ is zero:

$$
f\left(\mathbf{r}, \epsilon_{i}, \alpha_{j}\right)=0
$$



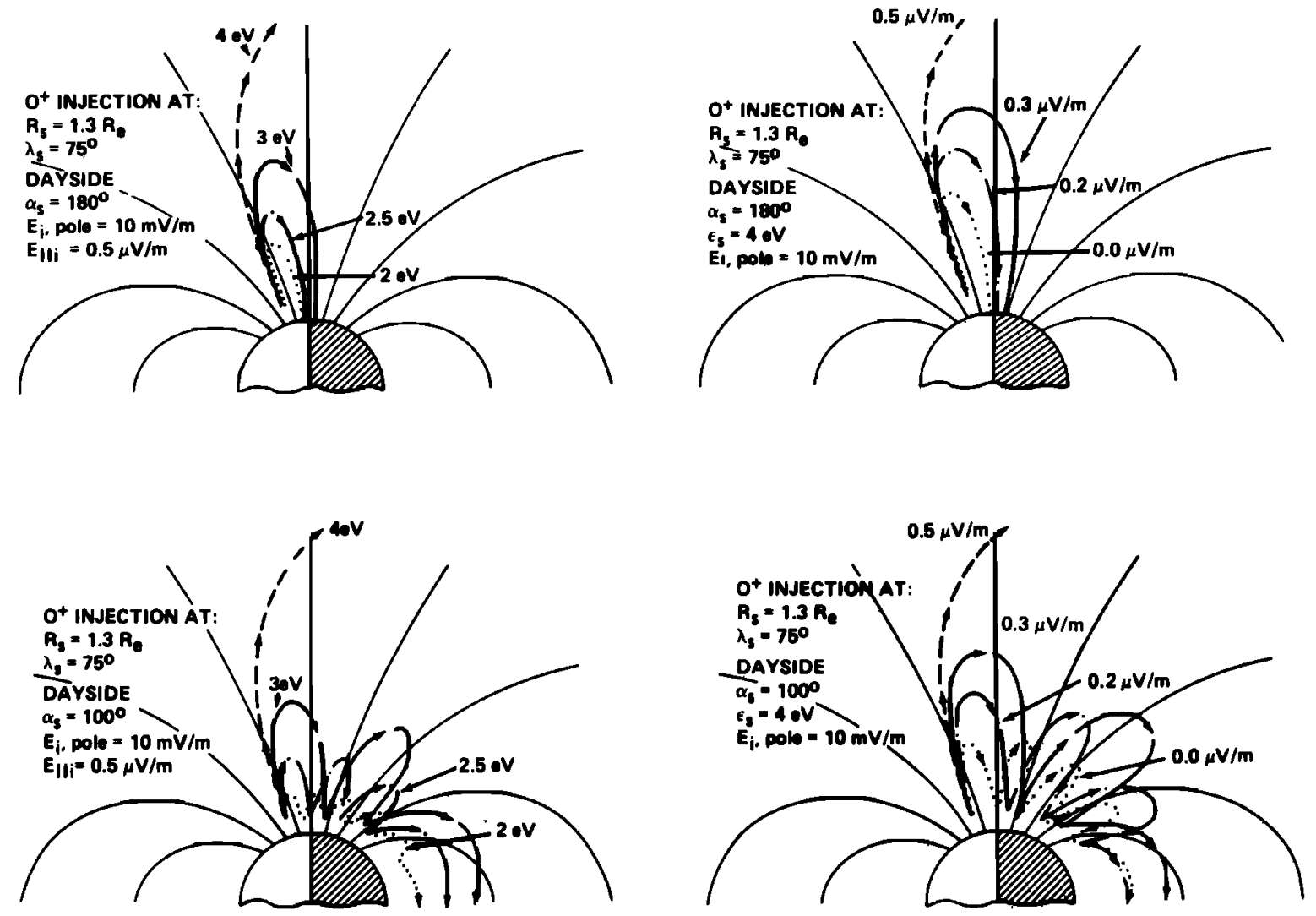

Fig. 3. Parabolic (upper panels) and hopping (lower panels) trajectories for various source energies at fixed $E_{\|, j}$ (left column) and various $E_{\|, i}$ for fixed source energies (right column).

if there is no intersection of the backward trajectory with the presumed source.

The distribution $f\left(r, \epsilon_{i}, \alpha_{i}\right)$ is also set to zero if, during the backward trajectory prior to intersection of the source region, the ion is under $640 \mathrm{~km}$, where atmospheric loss is considered to take place. This is obviously an oversimplification to the collisional and charge exchange effects on the ions as they move in the lower-altitude regions of the polar magnetosphere. If the trajectory does intersect the source location without having gone below the loss altitude, then the distribution function at $r$ (in the $E \times B$ drift rest frame) is

$$
f\left(\mathbf{r}, \epsilon_{i}, \alpha_{j}\right)=f_{s}\left(\epsilon_{i, \text { map }}, \alpha_{j, \text { map }}\right)
$$

In the above, $\epsilon_{i, \text { map }}, \alpha_{j, \text { map }}$ are the energy and pitch angle of the particle at the point of intersection of the source location $\mathbf{r}_{s}$, and $f_{s}\left(\epsilon_{i, \text { map }}, \alpha_{j, \text { map }}\right)$ is the source distribution, which is taken here to be the upgoing half of the biMaxwellian form as given in (4).

Having computed the distribution function array at location $\mathbf{r}, f\left(\mathbf{r}, \epsilon_{i}, \alpha_{j}\right)$, we use moment integrations of the distribution function to obtain various bulk parameters of interest. The three such parameters we consider here are the density, average parallel energy, and parallel flux, defined by

Density:

$$
n(\mathbf{r})=\iint f(\mathbf{r}, \epsilon, \alpha)\left(\frac{2}{m}\right)^{3 / 2} \pi \epsilon^{1 / 2} \sin \alpha d \alpha d \epsilon
$$

Parallel average energy:

$\epsilon_{\|}(\mathbf{r})=\iint f(\mathbf{r}, \epsilon, \alpha)\left(\frac{2}{\mathrm{~m}}\right)^{3 / 2} \pi \epsilon^{3 / 2} \cos ^{2} \alpha \sin \alpha d \alpha d \epsilon$

Parallel flux:

$F_{\|}(\mathbf{r})=\iint f(\mathbf{r}, \epsilon, \alpha)\left(\frac{2}{m}\right)^{2} \pi \epsilon \cos \alpha \sin \alpha d \alpha d \epsilon$

These calculations of distribution functions and the associated bulk parameters are performed at a series of regularly spaced locations as an array of grid points on a two-dimensional noon-midnight cross section of the polar magnetosphere. In each of the runs presented in this report, about $10^{6}$ ion trajectories were integrated, which generally consumed about 30-40 hours of CPU time on a VAX $11 / 780$.

It should be noted that the displays of the bulk parameters and distribution functions are only for those ions transported from the cleft ionosphere. These presumably should be superposed on those of the polar cap ionosphere produced by local photoionization and other effects.

\section{ION TRAJECTORIES IN THE POLAR MAGNETOSPHERE: EFFECT OF AMBIPOLAR PARALLEL ELECTRIC FIELD}

As has been noted above, Horwitz [1984] modeled the ion trajectories under the influence of gravity, magnetic mirror force, and convection, but no parallel electric field 
effects were included following injection. In this section we will illustrate some characteristic ion trajectories in which such effects are included. In Figure 1 we have injected lowenergy ionospheric ions of four different species $\left(\mathrm{H}^{+}\right.$, $\mathrm{He}^{+}, \mathrm{O}^{+}$, and $\mathrm{O}_{2}{ }^{+}$) at $3 \mathrm{eV}$ and $180^{\circ}$ pitch angle (i.e., directly up the magnetic field line in the northern hemisphere) at a representative cleft injection latitude $\left(75^{\circ}\right.$ on the dayside) and geocentric distance $\left(1.3 R_{E}\right)$. All of these ionospheric ions have been observed to be injected from the cleft region, with $\mathrm{H}^{+}, \mathrm{He}^{+}$, and $\mathrm{O}^{+}$reported by Moore et al. [1985], and recently Craven et al [1985] measured the molecular ions $\mathrm{N}_{2}^{+}, \mathrm{O}_{2}^{+}$, and $\mathrm{NO}^{+}$flowing up into the polar magnetosphere from the vicinity of the cleft. (Further, in the companion paper by Lockwood et al. [this issue], the cleft origin $\mathrm{N}^{+}$and $\mathrm{O}^{++}$are also reported within the polar magnetosphere.) The convection electric field at the ionospheric pole is specified with a nominal value of $50 \mathrm{mV} \mathrm{m} \mathrm{m}^{-1}$ in Figure 1 . The only difference between the upper and lower halves of Figure 1 is the value of $E_{\|, i}$ in the ionosphere, which is 0.0 and $0.5 \mu \mathrm{V} \mathrm{m}-1$, respectively. For this particular set of ion injection parameters, the species trajectory which seems most qualitatively sensitive to the difference in the $E_{\|, i}$ is $\mathrm{O}^{+}$. In the absence of $E_{\|, i}$ (top panel), the 3-eV $\mathrm{O}^{+}$executes a clear parabolic trajectory and falls into the polar cap atmosphere near $70^{\circ}$ on the nightside. The inclusion of an $E_{\|, i}=0.5 \mu \mathrm{V} \mathrm{m}^{-1}$ for the bottom panel eliminates most of the downward feature of the $\mathrm{O}^{+}$trajectory until the ion is well into the nightside region. It is interesting to note that in the trajectories of the other ions, both lighter and heavier ions appear to be only marginally affected by the $E \|_{i}$. In the case of the $\mathrm{O}_{2}{ }^{+}$, this is because the ratio of the gravitational to parallel electric-field-associated acceleration is significantly greater than unity for these ions even with $E_{\|, i}=$ $0.5 \mu \mathrm{V} \mathrm{m}^{-1}$, so that this $E \|_{, i}$ introduces a relatively minor perturbation on these molecular ions. In the case of the light ions, the $E \|_{i}$ yields a net upward acceleration, especially for $\mathrm{H}^{+}$, but the important consideration here is that for these particular energies and convection electric field value, the time scales for parallel and convectionassociated motion are such that the light ions do not convect very far antisunward from the field line of initial injection and are confined mainly to the dayside (up to the $5 R_{E}$ geocentric distance range displayed) even without the inclusion of a nonzero $E_{\|, i}$. Hence the importance of the $E_{\|, i}$ to the nature of the ion trajectory depends both on the ratio of the gravitational to parallel electric field and on the time scales for the parallel and convection motion.

Obviously, however, the inclusion of a parallel electric field can make a substantial difference in the light ion trajectories of low enough initial energies. For example, Figure 2 displays four $\mathrm{H}^{+}$trajectories for the pairs of initial energies 0.3 and $0.5 \mathrm{eV}$ and $E_{\|, i}$ of 0.0 and $0.5 \mu \mathrm{V} \mathrm{m}^{-1}$. These may be considered "polar wind" injection energies generally consistent with observations at slightly lower altitudes by Hoffman and Dodson [1980]. It should be stressed that although in Figure 2 these $\mathrm{H}^{+}$ions are injected at the cleft latitudes, we are not suggesting that the major source of light ions at very low energies is restricted to this region, as appears to be the case for $\mathrm{O}^{+}$and other heavy ions [Lockwood et al, this issue]. In this case, in the absence of a parallel electric field, there is strong antisunward transport within the $<5 R_{E}$ region displayed, and there is also a fairly significant separation between the 0.3 and $0.5-\mathrm{eV} \mathrm{H}{ }^{+}$ion trajectories. The effect of including an $E_{\|, i}=0.5 \mu \mathrm{V} \mathrm{m} \mathrm{m}^{-1}$ is to accelerate ions of both initial energies rapidly up the magnetic field lines so that they are confined to the rayside in this case for the region displayed, and there is little remaining separation between the trajectories.

Owing to the assumed $1 / r^{2}$ form of the $E \|$ distribution (equation (1)), most of the net difference in ion energization occurs over about $1 R_{E}$ when the injection is near the ionosphere. Hence different combinations of the initial ion energy and $E \|_{, i}$ can yield quite similar characteristic trajectories. This point is illustrated in Figure 3. In the top left panel of Figure $3, \mathrm{O}^{+}$ions are injected at $\alpha=180^{\circ}$ (i.e., field aligned) for a range of initial energies at a constant $E \|_{, i}$ of $0.5 \mu \mathrm{V} \mathrm{m} \mathrm{m}^{-1}$ and a low-convection electric field of $10 \mathrm{mV} \mathrm{m} \mathrm{m}^{-1}$ at the ionosphere. In this case the characteristic parabolic trajectories occur for energies below $3 \mathrm{eV}$. In the top right panel the initial energy is fixed at $4 \mathrm{eV}$ and trajectories are presented for a range of $E \|_{,}$, and here the parabolic trajectories occur for $E \|_{, i}$ less than about $0.3 \mu \mathrm{V} \mathrm{m} \mathrm{m}^{-1}$. The "tradeoff" between injection energy and $E \|_{, i}$ can be seen in the similarity of trajectories for these two top panels for different combinations of these parameters. Indeed, the $\mathrm{O}^{+}$trajectories for $3 \mathrm{eV}$ and 0.5 $\mu \mathrm{V} \mathrm{m} \mathrm{m}^{-1}$ in the top left panel and for $4 \mathrm{eV}$ and $0.2 \mu \mathrm{V} \mathrm{m}^{-1}$ in the top right panel are almost identical. In the bottom two panels the same parameters were used, except that the $\mathrm{O}^{+}$ions for this case were injected with $\alpha=100^{\circ}$ (i.e., nearly perpendicular). As is indicated in these panels, for low enough injection energy and/or $E \|_{, i}$, this leads to the "hopping" trajectories described by Horwitz [1984]. The same types of tradeoffs between initial injection energies and $E_{\|, i}$ are evident in these trajectories as for the field-aligned injection and parabolic trajectories in the upper panels of Figure 3.

\section{ION DISTRIBUTIONS IN THE POLAR MAGNETOSPHERE AS SUPPLIED BY A CLEFT IONOSPHERE ION FOUNTAIN: A TWO-DIMENSIONAL KINETIC MODEL}

As was discussed in section 2, we use the ion trajectory code to obtain distribution functions as supplied by a source region which we ordinarily identify with the cleft ionosphere. In this section our objective is primarily to introduce this two-dimensional kinetic model and illustrate some of the interesting effects by showing some results for different source conditions. We anticipate that there will be subsequent reports directed toward detailed investigation of some of the points touched on in this section. We also intend to examine distributions of energetic ions in the tail lobes as predicted by this model, somewhat along the lines of the Pilipp and Morfill [1978] work, but for the ionospheric ions supplied by the cleft as opposed to the solar wind protons in the mantle as considered in that work.

Figure $4 a$ displays the contoured bulk parameters of density, parallel average energy, and parallel fluxes within the polar magnetosphere as supplied by the cleft ion fountain for $\mathrm{O}^{+}$for two different convection electric fields. In the left-hand column are these contoured bulk parameters for source conditions of an upgoing half of a biMaxwellian with a density of $1000 \mathrm{O}^{+} \mathrm{cm}^{-3}$ and perpendicular and parallel ion thermal energies of 10 and $1 \mathrm{eV}$, 
SOURCE:

$A_{1}=1.4 A_{0}$

$\lambda=70-73^{\circ}$

DAYSIDE

$n_{1}-10000^{+} / 10$

$n_{1}=100 \mathrm{~V}$

$T_{\| 1 / 2}=10 \mathrm{~V}$

$K T_{118}=1 \in V$
$E_{1, D 0 w}=20 \mathrm{mV} / \mathrm{m}$
$E_{11,1}=0.5 \mu \mathrm{V} / \mathrm{m}$

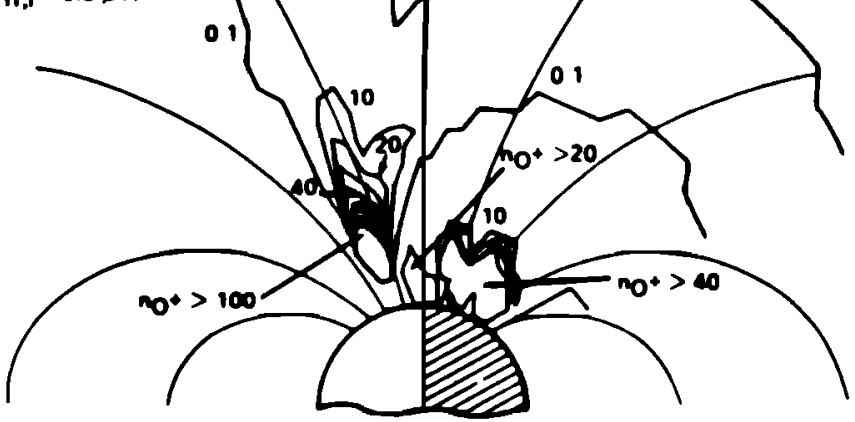

DENSITIES $10^{\circ} \mathrm{CCI}$

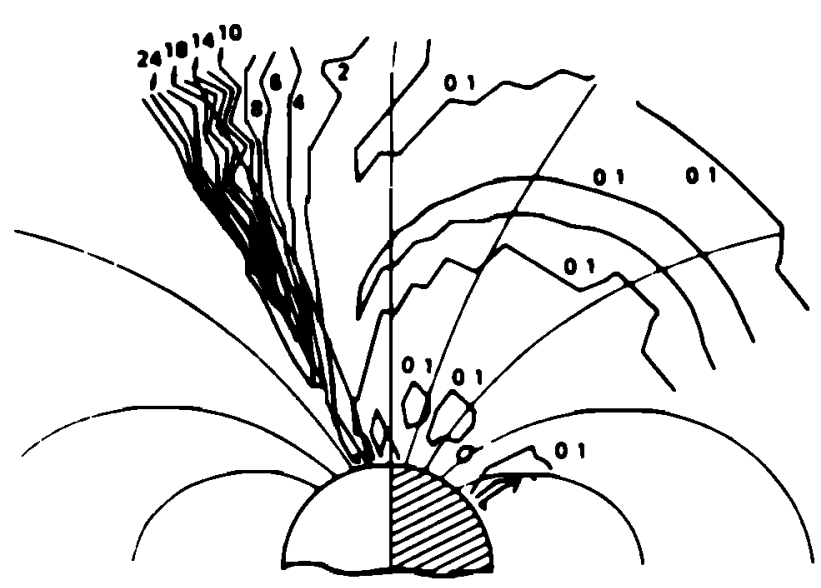

parallel average eneagies (Ev)

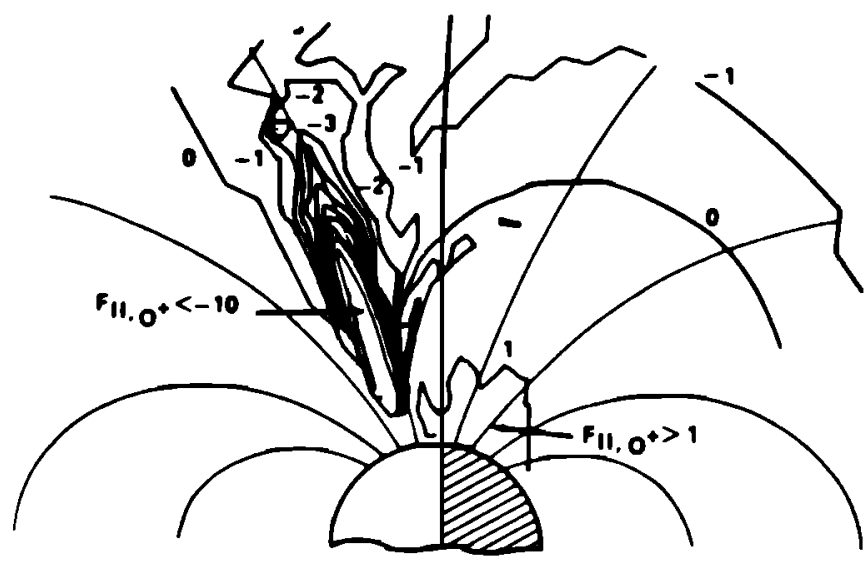

PARALLEL FLUXES $\left(10^{6} 0^{7}\left(\mathrm{~cm}^{2}\right.\right.$. a $\left.)\right)$
SOUACE:

$R_{3}=1.4 R_{8}$

$\lambda=70-73^{\circ}$

DAYSIOE

$n_{s}=10000^{+} / \mathrm{ce}$

$k T_{18}=100 \mathrm{~V}$

$k T_{H_{s}}=10 \mathrm{~V}$

$E_{1, p o l o}-80 \mathrm{mV} / \mathrm{m}$

$E_{H, 1}=0.5 \mu \mathrm{V} / \mathrm{m}$
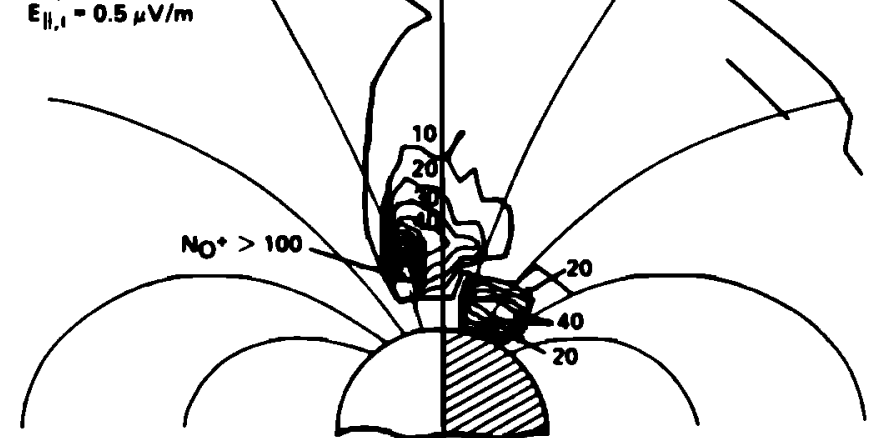

DENSITIES $\left.10^{+} / \mathrm{CC}\right)$

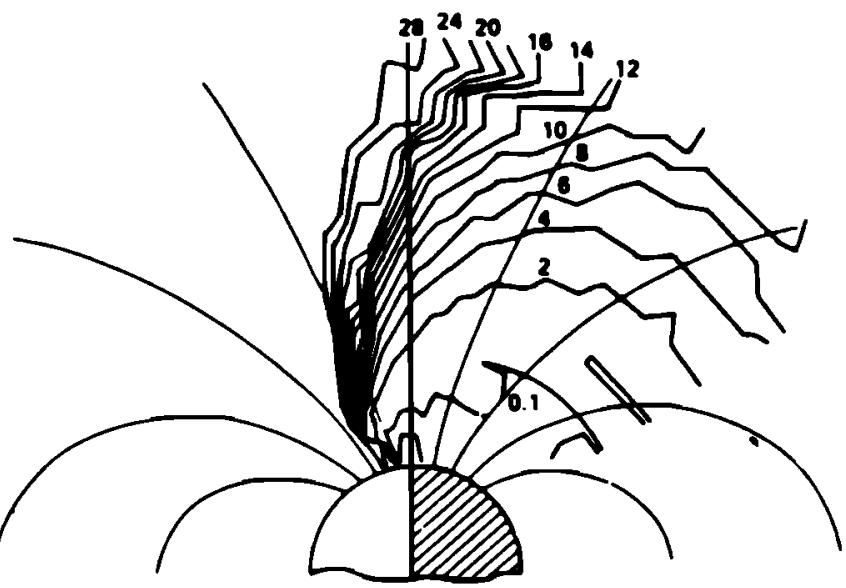

parallel average energies (ev)

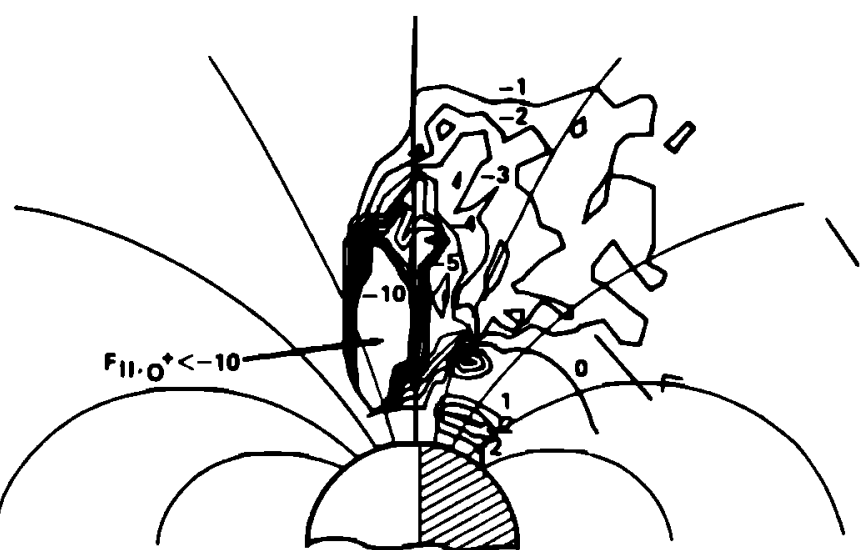

PARALlel FluXes $\left(10^{6} \mathrm{O}+/\left(\mathrm{cm}^{2}-1\right)\right)$

Fig. 4a. Bulk parameters of $\mathrm{O}^{+}$in the polar magnetosphere for two sets of conditions describing the characteristics of the cleft ion fountain. Principal features illustrated are the enhanced filling of the polar magnetosphere during increased convection (contrasting the left and right top panels of density) and the corresponding energy dispersion with convection seen in the contrast of the middle panels of these two columns.

respectively. This source distribution is considered to be located at $1.4 R_{E}$ geocentric distance between $70^{\circ}$ and $73^{\circ}$ magnetic latitude on the dayside, and there is an ionospheric parallel electric field of $0.5 \mu \mathrm{V} \mathrm{m} \mathrm{m}^{-1}$. The convection electric field in the left column is $20 \mathrm{mV} \mathrm{m}^{-1}$, whereas in the right column it is $80 \mathrm{mV} \mathrm{m}^{-1}$, with all other parameters being the same. The source parameters are essentially similar to the general distribution functions 

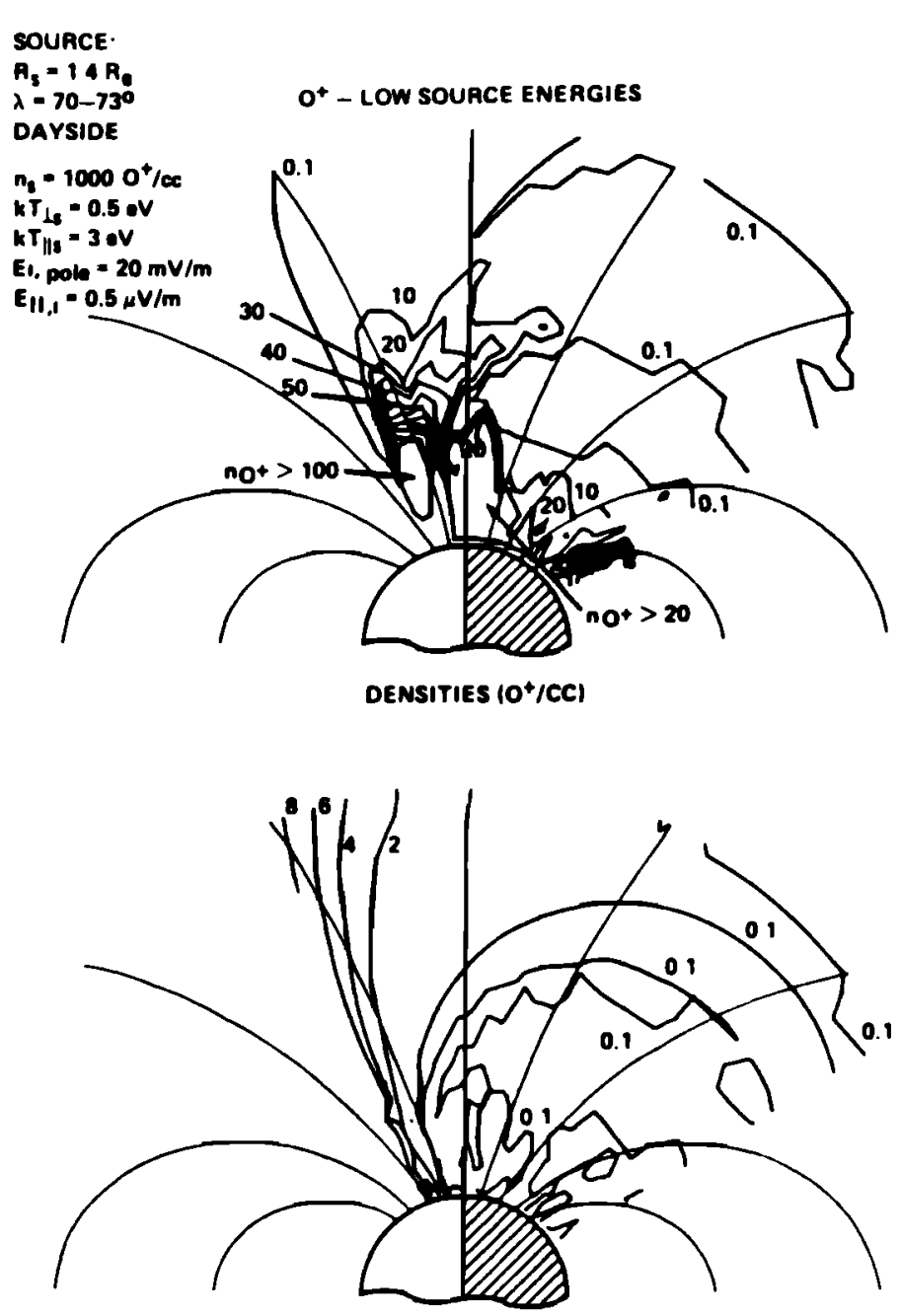

parallel average energies (eV)

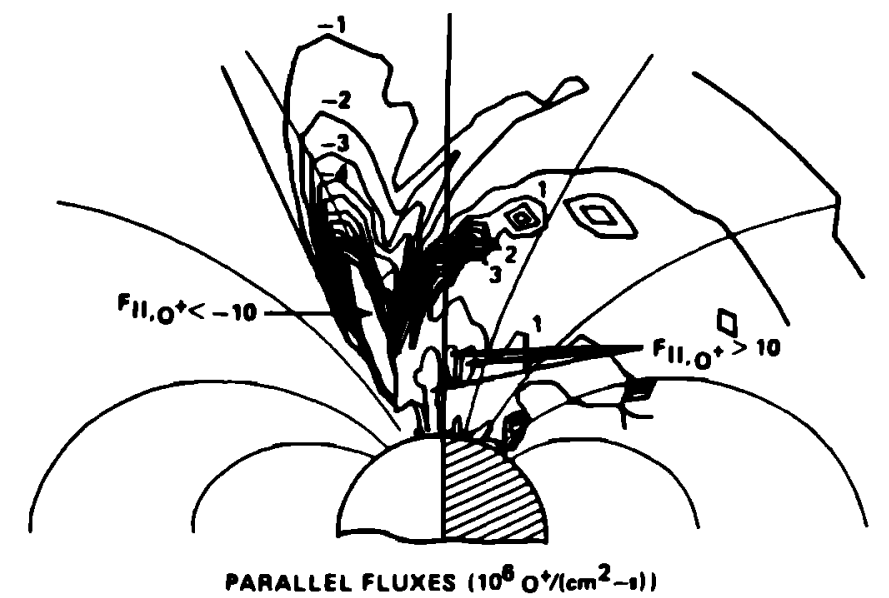

Fig. 4b. Similar to the left column of Figure $4 a$ for lower source energies and reversed temperature anisotropy. Note the evidence of significant downward flows of $\mathrm{O}^{+}$when source energies are well below escape energies. This is illustrated best in the flux plot in the lower panel, where substantial downward (positive) fluxes are evident in the central polar cap low-altitude region.

reported for a cleft upwelling ion event by Moore et al. [1984]. In Figure $4 b$ the parameters are the same as for the left-hand column of Figure $4 a$ except that we have lowered the source energies and reversed the temperature anisotropy so that the parallel and perpendicular thermal energies are 3 and $0.5 \mathrm{eV}$, respectively.

The contrast between the left and right columns in Figure $4 a$ illustrates the effects of the convection electric field on these $\mathrm{O}^{+}$distributions. For the $20 \mathrm{mV} \mathrm{m}^{-1}$ lowconvection case illustrated in the left column, the density contours are largely confined to the dayside, and indeed, the principal density decline from the source region is mainly due to the divergence of the magnetic field. The parallel average energies in the left middle panel of Figure $4 a$ also show confinement to the dayside part of the polar magnetosphere, with the contours of 24 through $2 \mathrm{eV}$ being relatively closely bunched toward the field lines threading the source region. As is indicated in the bottom left panel of Figure $4 a$, the parallel fluxes for this case are negative (upward) in this dayside region. Increasing the convection electric field to $80 \mathrm{mV} \mathrm{m}^{-1}$, as in the right column, causes the $\mathrm{O}^{+}$to spread much farther into the nightside polar magnetosphere, with significant densities of the order of $10-40 \mathrm{O}^{+} \mathrm{cm}^{-3}$ observed in the central and nightside polar magnetosphere in the vicinity of $\sim 2 R_{E}$ altitude. There is significant energy dispersion now seen in the right middle panel of Figure $4 a$, and all energy contours below $28 \mathrm{eV}$ spread into the nightside polar magnetosphere, especially those less than about $10 \mathrm{eV}$, and those below 8 $\mathrm{eV}$ reach latitudes typical of the nightside auroral oval.

Three sample velocity distribution functions at different locations appropriate to the conditions in the right column of Figure $4 a$ are contour plotted in Figure 5 in the $\mathrm{E} \times$ $B / B^{2}$ reference frame. Essentially, the source distribution function is displayed in the left panel of Figure 5; it is the expected shape of the upgoing half of a bi-Maxwellian except that the contours do not quite extend all the way to the $v_{\perp}$ axis owing to a slight resolution coarseness in both the velocity space grid and the contouring routine. In the middle panel is shown the distribution at a somewhat higher altitude, with reductions in density due to both magnetic field divergence and strong convection of the plasma away from the source region. A conical distribution is clearly evident in this middle panel as the initial biMaxwellian "folds" toward the magnetic field line direction. The right-hand panel shows the $\mathrm{O}^{+}$distribution function at $3 R_{E}$ directly over the geomagnetic pole and thus fairly far away from the narrow cleft source region. The interesting aspect of this distribution is that only a narrow region of velocity space is occupied around a "centroid" located at about $v_{\|} \sim 10 \mathrm{~km} \mathrm{~s}^{-1}$ upward. We will comment on this point in the discussion section. We intend to explore much further the character of these predicted distribution functions and compare them with measurements by DE 1 in subsequent investigations.

The effect of lowering the source energies is shown in Figure $4 b$. The most conspicuous effect is the enhancement of the plasma densities in the $r<2 R_{E}$ central polar cap, as compared with the higher-energy source in the left-hand column of Figure $4 a$. This is mainly the result of the parabolic flow of $\mathrm{O}^{+}$from the cleft source into this region. In the bottom panel this relatively low altitude central polar cap region is seen to contain relatively high downward fluxes of $\mathrm{O}^{+}$, in some instances exceeding $10^{7} \mathrm{O}^{+}$ $\left(\mathrm{cm}^{2} \mathrm{~s}\right)^{-1}$. Note also the distinct additional region of downward flow near $2.5 R_{E}$ directly over the pole. These regions of downward flow may be compared with the $\mathrm{O}^{+}$ trajectory plots in Figures 1 and 3, although those trajec- 


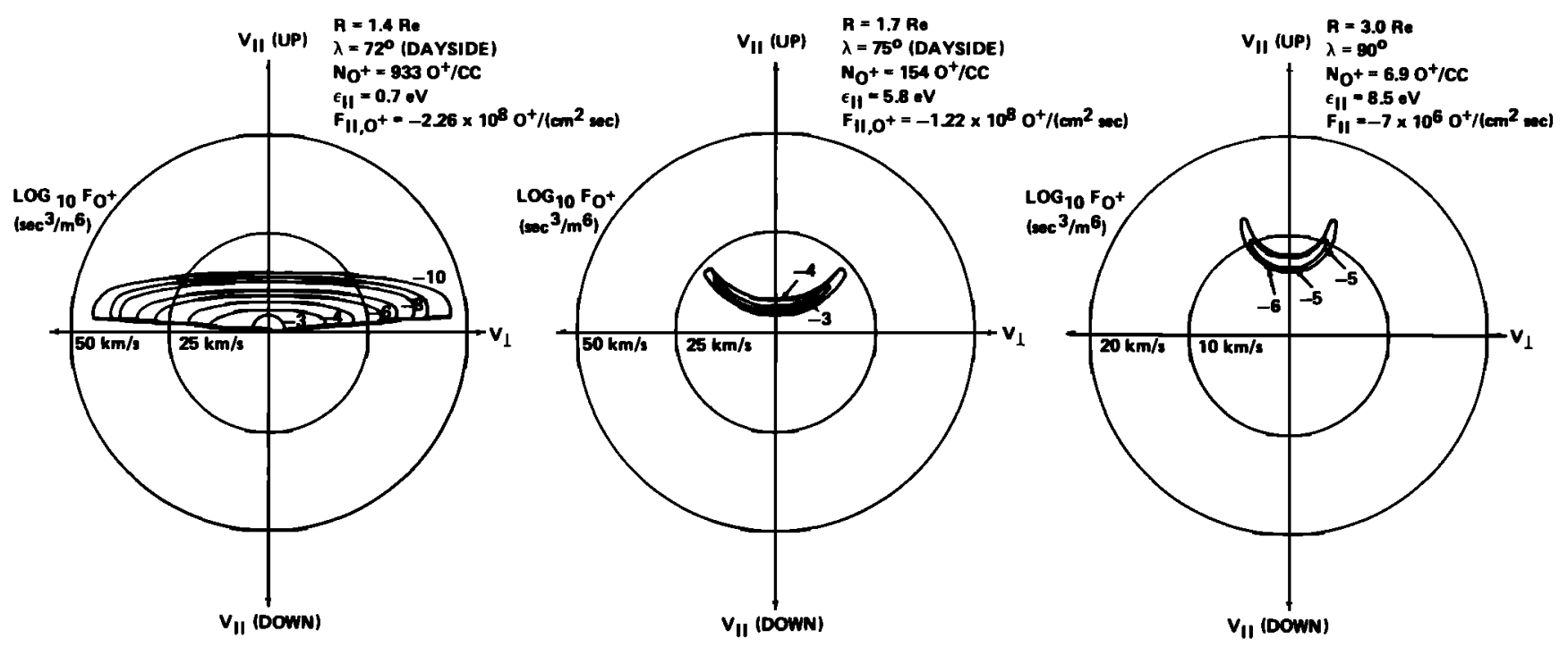

Fig. 5. Sample velocity distributions of $\mathrm{O}^{+}$(in the $\mathrm{E} \times \mathrm{B} / B^{2}$ reference frame) appropriate to the source and field conditions described for the right column of Figure 4a. From left to right, these distribution functions are from the specified source region, somewhat above and antisunward of the source, and over the pole at moderately high altitudes distant from the cleft source.

tories were for ionospheric convection electric fields of 50 and $10 \mathrm{mV} \mathrm{m}^{-1}$, respectively, as opposed to the $20 \mathrm{mV} \mathrm{m}^{-1}$ electric field in Figure $4 b$. Of course, there are also $\mathrm{O}^{+}$ downward flows in Figure $4 a$, but at smaller intensities in these cases because, owing to the higher source energies, a smaller fraction of the cleft source $\mathrm{O}^{+}$ions are gravitationally bound than in Figure $4 b$. In Figure 6 the parameters are similar to those in Figure $4 \dot{b}$, except that the source distribution has been widened and $E \|_{i}$ set to 0.0 , which enhances in particular the downward fluxes in the central and nightside polar cap.

In Figure 7 we have reversed the temperature anisotropy back so that $k T_{\perp}=3 \mathrm{eV}$ and $k T \|=0.5 \mathrm{eV}$ and run this case for two values of $E \|_{, i}, 0.5$ and $0.0 \mu \mathrm{V} \mathrm{m}-1$. Although the density and flux contours are rather complex and dense for the nightside, $r<2.5 R_{E}$, region in this case, we wish to point out one new interesting effect, seen reasonably well in the lower left panel of Figure 7, where the parallel fluxes for the $E_{\|_{i} i}=0.5 \mu \mathrm{V} \mathrm{m} \mathrm{m}^{-1}$ case are plotted. Examining the callouts to the fluxes, we see a region above the source where the fluxes are negative or upward, then a region over the pole where the fluxes are downward, and finally, further into the nightside region, a third region where the fluxes are again upward. This is evidently a "hopping" flow of $\mathrm{O}^{+}$ions from the cleft source, consistent with the single-ion trajectories shown in the bottom of Figure 3 .

Although the major focus of this particular work is on the features of the two-dimensional $\mathrm{O}^{+}$flow from a narrow, cleft-associated source region, it is useful in this context to indicate some of the possible features of low-energy light ions that should emerge from a broader region of the polar cap. Figure 8 displays two plots depicting the results of assuming an $\mathrm{H}^{+}$source with the upgoing half of a biMaxwellian form having a density of $1000 \mathrm{H}^{+} \mathrm{cm}^{-3}$ and $k T_{\|}=1 \mathrm{eV}$ and $k T_{\perp}=0.5 \mathrm{eV}$ distributed between $70^{\circ}$ on the dayside to $80^{\circ}$ on the nightside, under conditions of a $50 \mathrm{mV} \mathrm{m}^{-1}$ convection electric field and 0.0 and $1 \mu \mathrm{V} \mathrm{m} \mathrm{m}^{-1}$ ionospheric parallel electric fields. In a very rough sense this might contain some elements of the transport effects on a classical polar wind source, but we feel that more information on the detailed characteristics of the classical polar wind should be obtained from the DE 1 observations before a serious attempt is made to model its high-altitude transport in detail using the present technique. Nevertheless, the cases depicted in Figure 8 should indicate the general features of transport of such light ions from a broad source region. Here the field divergence accounts for most of the $\mathrm{H}^{+}$density decline from source, with the parallel electric field in the right column further causing a decrease with altitude. This latter effect arises because the fluxes are nearly constant along a flux tube, so that as the accelerating parallel electric field increases the parallel velocity, the density must correspondingly decrease to roughly conserve flux in a magnetic flux tube. The effects of the accelerating parallel electric field may be seen directly in the pronounced enhancement of the parallel average energies in the middle of the right column of Figure 8 as compared with the left column, which had $E_{\|, i}=0.0$.

\section{DISCUSSION}

The basic features of the present two-dimensional model of the cleft ion fountain are consistent with the recent lowenergy ion observations by the DE 1 satellite. The observed features include the following:

1. The Kp-dependent extension of measurable $\mathrm{O}^{+}$ fluxes into the central and nightside polar magnetosphere [Lockwood et al., this issue]. As depicted in the present model, this observation is viewed as partly the result of the increasing dawn-dusk convection electric field with $K p$ "blowing" the $\mathrm{O}^{+}$from the cleft source into the polar magnetosphere. This is illustrated in the present work by the comparison of the left and right columns of Figure $4 a$.

2. The energy and mass dispersion of the ionospheric ions injected from the cleft is such that the lowest-energy/ highest-mass ions extend farthest toward the nightside from the cleft. This effect is evident in the ion spectrograms of 

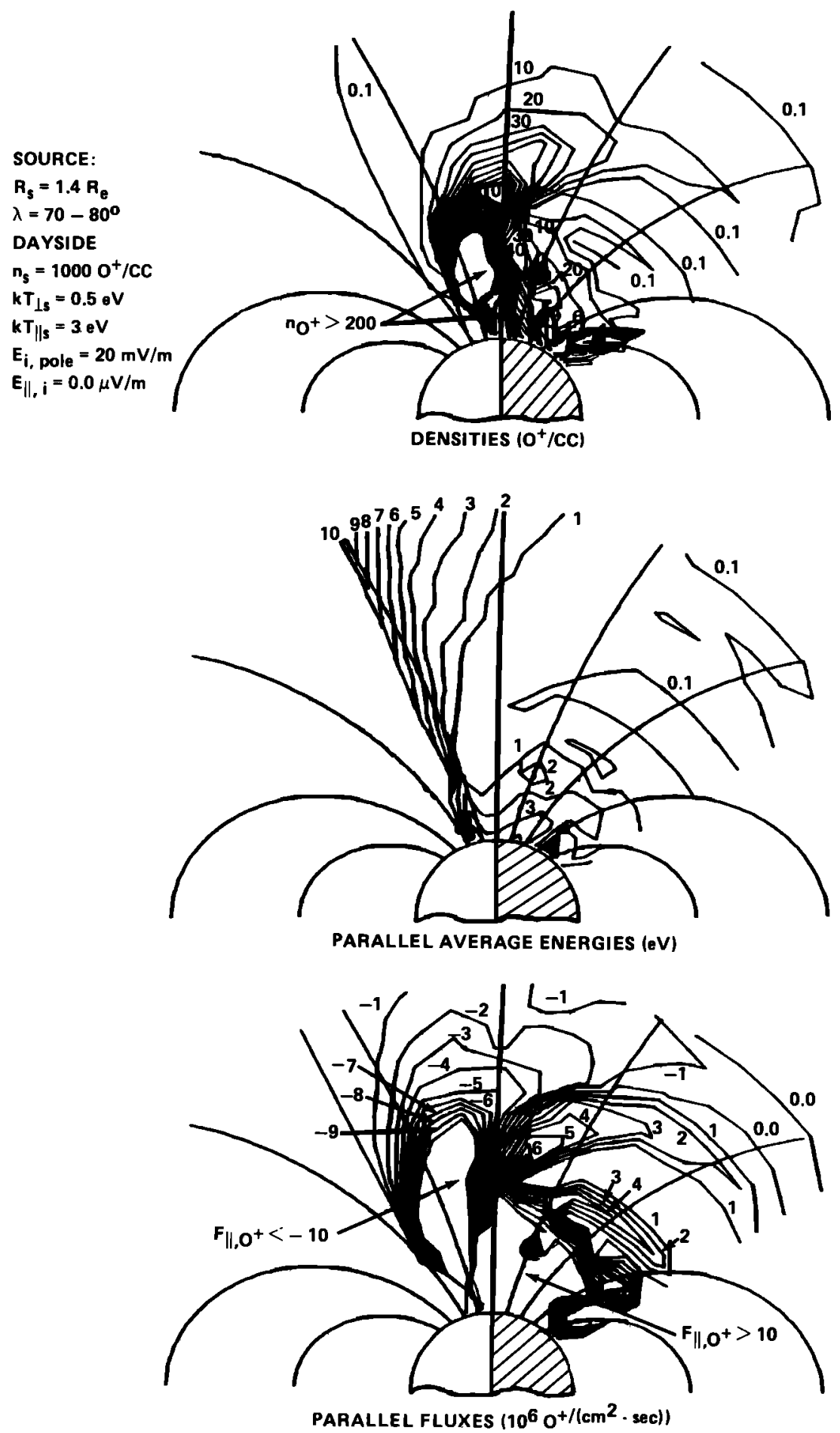

Fig. 6. Distribution of $\mathrm{O}^{+}$bulk parameters in the polar magnetosphere for fountain characteristics similar to the case in the right column of Figure $4 a$, but with $E_{\|, i}=0.0$ and the cleft source width expanded to $10^{\circ}$. Even greater downward fluxes exceeding $10^{7} \mathrm{O}^{+}\left(\mathrm{cm}^{2} \mathrm{~s}\right)^{-1}$ are evident in the nightside low-altitude polar cap.

Moore et al. [1985] and compares well with the model, for example, Figure 2 and the parallel average energy contour plots in Figures 4, 6, 7, and 8 .

3. Downward flow of very low-energy $\mathrm{O}^{+}$ions in the central polar cap has been observed by Lockwood et al. [this issue]. This seems entirely consistent with the concept of parabolic flow of gravitationally bound $\mathrm{O}^{+}$from the cleft ionospheric source to the central and nightside polar cap, as depicted in some of the $\mathrm{O}^{+}$trajectories in Figures 1 and 3 , and parallel fluxes in the contour plots, particularly in the bottom of Figure $4 b$.

Recently, Gallagher et al. [1984] have reported outflowing $\mathrm{O}^{+}$at high altitudes over the polar cap with densities of $\sim 20 \mathrm{O}^{+} \mathrm{cm}^{-3}$ together with outflowing $\mathrm{H}^{+}$of about $10 \mathrm{H}^{+} \mathrm{cm}^{-3}$ and an $\mathrm{H}^{+}$"isotropic background" of about 15-20 $\mathrm{H}^{+} \mathrm{cm}^{-3}$, for a total plasma density, measured inde- 

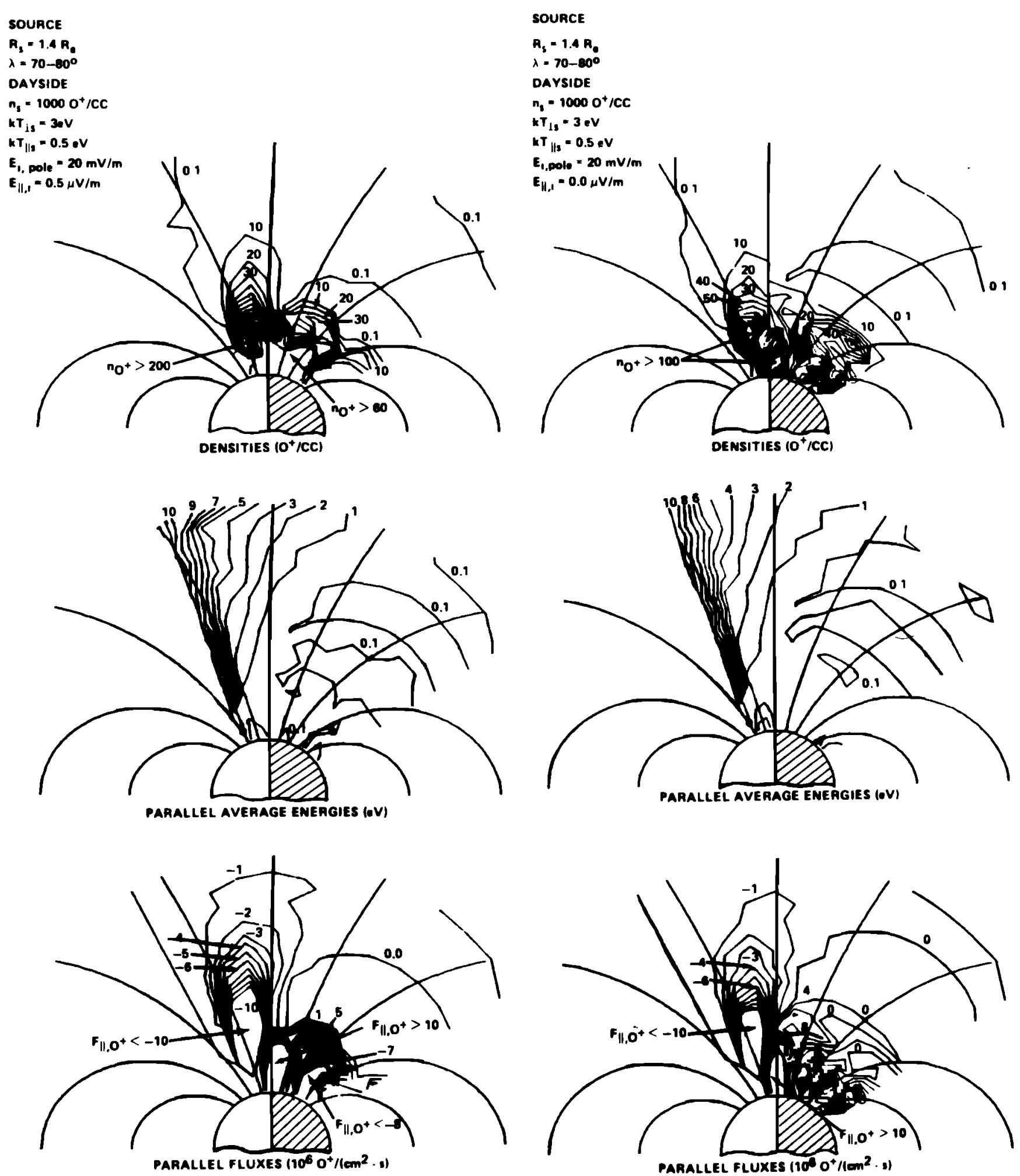

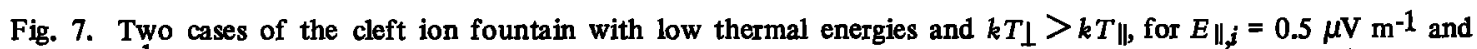
$0.0 \mu \mathrm{V} \mathrm{m}^{-1}$. Although the flux and density contours are dense and complex for this case, note the upward, then downward, then upward fluxes seen in the low to intermediate-altitude regions moving antisunward across the polar cap, indicating a hopping flow of $\mathrm{O}^{+}$.

pendently using plasma wave observations, of about 50 $\mathrm{cm}^{-3}$. These $\mathrm{O}^{+}$densities are consistent, within a factor of 2 or so, of the $\mathrm{O}^{+}$density in the right column of Figure $4 a$ or Figure $4 b$, for example, while the $\mathrm{H}^{+}$densities are similar to those in the right-hand column of Figure 8.
Assuming that the $\mathrm{H}^{+}$isotropic background was due to a partial isotropizing mechanism (e.g., wave-particle interactions) operating on the flowing $\mathrm{H}^{+}$, the combination of a broad $\mathrm{H}^{+}$polar cap source region such as that depicted in Figure 8 together with the narrow $\mathrm{O}^{+}$ion fountain asso- 
ciated with the cleft is consistent with these data. A similar suggestion has been made by Green and Waite [1985].

In this introductory paper we have not attempted to address systematically the suggestion by Lockwood et al. [1985] that this cleft source region could be a significant "feeder" of $\mathrm{O}^{+}$into the $\sim 1-2 R_{E}$ altitude nightside acceleration region, where energetic $\mathrm{O}^{+}$ions are observed in upflowing ion events [e.g., Gorney et al., 1981; Ghielmetti et al., 1978]; however, we can make some general comments. It is evident that the combination of convection electric field and ion energy must be high enough and low enough, respectively, so that an ion is not ejected onto too high a trajectory such that it might "overshoot" the nightside acceleration region. For instance, the light ions in Figure 1 clearly will escape into the tail lobes and the nightside region well above the acceleration location. On the other hand, if the energies and convection are too low, the downward flow into the polar cap atmosphere could terminate any significant $\mathrm{O}^{+}$fluxes from reaching the nightside acceleration region. However, two effects may work against this last apparent consequence to assist more of the low-energy cleft $\mathrm{O}^{+}$into the nightside auroral acceleration region. One of these is the parallel electric field, which will tend to "buoy" the $\mathrm{O}^{+}$from falling into the atmosphere and allow it to be transported further antisunward. Indeed, if the parallel electric field were set to precisely the value to compensate for the gravitational force for a given ion such as $\mathrm{O}^{+}$, then even the lowestenergy ions would be still transported onto nightside auroral field lines above the source altitude. The other effect that can assist the transport of the lower-energy ions to the nightside without their falling down first is the magnetic mirror force. This produces the "hopping" $\mathrm{O}^{+}$ trajectories in Figure 3, so that ions whose energy would lead them to fall and be lost in the polar cap atmosphere will instead be reflected upward and allowed to be transported further into the nightside. This can be seen to some extent in the comparison of the $\mathrm{O}^{+}$densities (top panels) in the nightside $r<2.5 R_{E}$ regions of Figure 6 and the right column of Figure 7, where the only difference in the parameters for these two cases is in the direction of source temperature anisotropy. We can see that the case in the right column of Figure 7, whose source has $k T_{\perp}=3$ $\mathrm{eV}$ and $k T \|=0.5 \mathrm{eV}$, leads to larger densities, by factors of 4 or more, in this region than the case in Figure 6, which has $k T_{\perp}=0.5 \mathrm{eV}$ and $k T_{\|}=3 \mathrm{eV}$. Hence the mirror force seems to assist the low-energy ions onto the nightside auroral field lines.

We can estimate the feasibility of the cleft fountain's supplying sufficient $\mathrm{O}^{+}$fluxes for nightside energization by evaluating the perpendicular or convected flux of $\mathrm{O}^{+}$ions across an auroral $L$ shell per unit length in the longitudinal direction, integrating this flux with altitude up to the altitude of observed energetic $\mathrm{O}^{+}$, and dividing this quantity by the width of an arc at this altitude. This gives an estimate of the potential $\mathrm{O}^{+}$parallel flux which could be emerging on the nightside auroral field lines as

$$
F_{\|, \mathrm{O}^{+}, \text {nightside }}=\left(\int n_{\mathrm{O}^{+}}(\mathrm{s}) y_{\perp}(s) d s\right) / w(\operatorname{arc})
$$

where the integral is along a nightside arc $L$ shell up to the acceleration altitude, $v_{\perp}$ is the local convection velocity, and $w(\operatorname{arc})$ is the high-altitude latitudinal width of an arc in which these fluxes may be considered to emerge. Using the results for the density and convection velocity for the case of Figure $4 b$, integrating up to $r=2 R_{E}\left(1 R_{E}\right.$ altitude) at an $L$ shell intersecting $70^{\circ}$ invariant latitude, and taking the width of an arc at this $r=2 R_{E}$ location to be $\sim 400 \mathrm{~km}$, we estimate a potential $\mathrm{O}^{+}$number flux in such a nightside arc to be of the order of $3 \times 10^{7} \mathrm{O}^{+}\left(\mathrm{cm}^{2} \mathrm{~s}\right)^{-1}$. In this connection, it is interesting to note that in the observations of Collin et al. [1981] from the auroral acceleration region, the nightside auroral $\mathrm{O}^{+}$fluxes were always $<5 \times 10^{7} \mathrm{O}^{+}\left(\mathrm{cm}^{2} \mathrm{~s}\right)^{-1}$ for energies above $0.5 \mathrm{keV}$, and more recently, Yau et al. [1984] found that $\mathrm{O}^{+}$fluxes for energies greater than $10 \mathrm{eV}$ in the auroral zone rarely exceeded $10^{7} \mathrm{O}^{+}\left(\mathrm{cm}^{2} \mathrm{~s}\right)^{-1}$. Hence the cleft ion fountain is at least a possible source for these energetic nightside $\mathrm{O}^{+}$fluxes. The other potential source of these energetic $\mathrm{O}^{+}$fluxes is flow directly up along nightside auroral field lines. Large upward $\mathrm{O}^{+}$flows (of the order of $10^{9} \mathrm{O}^{+}$ $\left.\left(\mathrm{cm}^{2} \mathrm{~s}\right)^{-1}\right)$ in the nightside auroral ionsophere have been deduced from topside soundings near $600-\mathrm{km}$ altitude by Lockwood and Titheridge [1981]. However, the flows reported by Lockwood and Titheridge [1981] were of unheated ionsopheric $\mathrm{O}^{+}$, and without low-altitude acceleration, these ions would convect sunward over large distances around the auroral oval before reaching the acceleration altitude. Lockwood [1982] showed the lowaltitude $\mathrm{O}^{+}$flows to occur mainly in the night and morning local time sectors, and hence, allowing for the effect of convection, a large part of this outflow could be entering the cleft ion fountain before being returned to the nightside over the polar cap: in effect, the $\mathrm{O}^{+}$may move around much of a convection .cell in attaining the altitude of acceleration on the nightside. It is interesting, therefore, to compare the average total $\mathrm{O}^{+}$outflow in the cleft ion fountain, which has a minimum of $10^{25}$ ions $\mathrm{s}^{-1}$ [Lockwood et al., $1985]$, with the total $\mathrm{O}^{+}$outflow at $\sim 600-\mathrm{km}$ altitude similarly deduced from the results of Lockwood [1982], which is about $2 \times 10^{25}$ ions $s^{-1}$ (M. Lockwood, unpublished manuscript, 1985). This, therefore, may imply that a significant fraction of the $\mathrm{O}^{+}$is cycled through the cleft ion fountain.

A final brief comment is in order with respect to the character of the ion velocity distribution function, in regions distant from the cleft source. We noted that the $\mathrm{O}^{+}$distribution in the right side of Figure 5 , at $r=3 R_{E}$ over the geomagnetic pole, occupies a relatively small region of velocity space near $\sim 10 \mathrm{~km} \mathrm{~s}^{-1}$ in the upward field-aligned direction. A flowing Maxwellian distribution "fit" to such types of distributions would often yield supersonic characterizations of the distributions. Although it is possible or perhaps likely that self-instabilities and/or other effects in the polar magnetospheric environment would work to "isotropize" the distribution and wash out the conical shape, such effects would probably leave a distribution with the basic character of a flowing Maxwellian with substantial Mach number. What is interesting is that the source distribution, apart from being highly anisotropic, is characterized by a rather low Mach number, yet distant from this source is found a high Mach number distribution. This does not result from an acceleration due to the parallel electric field because the net force on the ions resulting from the gravitational and parallel electric fields is still downward. Instead, the reason that only a small region of 
SOURCE.

$A_{8}=1.4 A_{8}$

$\lambda=70^{\circ}$ (DAY)

$-80^{\circ}$ (NIGHT)

$n_{1}-1000 \mathrm{H}^{+} / \mathrm{CC}$

$k T_{18}-0.5 \mathrm{eV}$

$k T_{\| \mathbf{z}}=1, \mathrm{~V}$

$E_{1,0.0}=50 \mathrm{mV} / \mathrm{m}$

$E_{11,1}=0.0 \mu \mathrm{V} / \mathrm{m}$

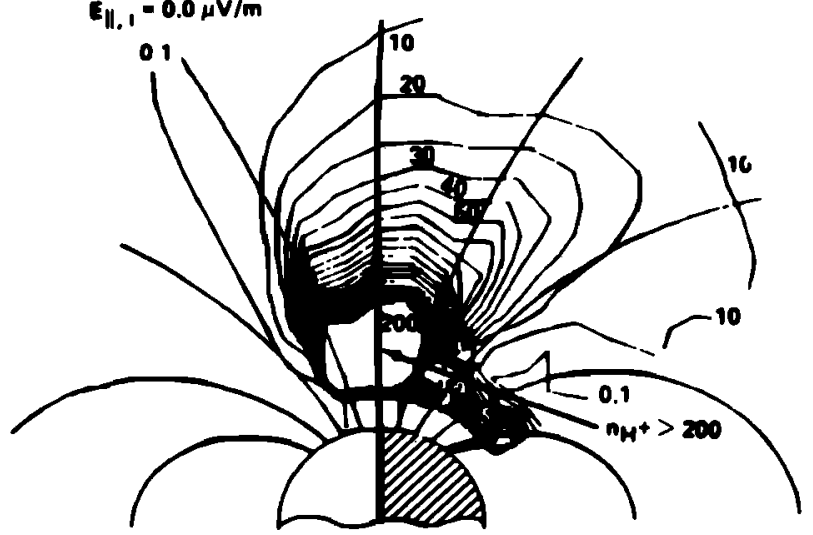

DENSITIES $\left(M^{+} / C C\right)$

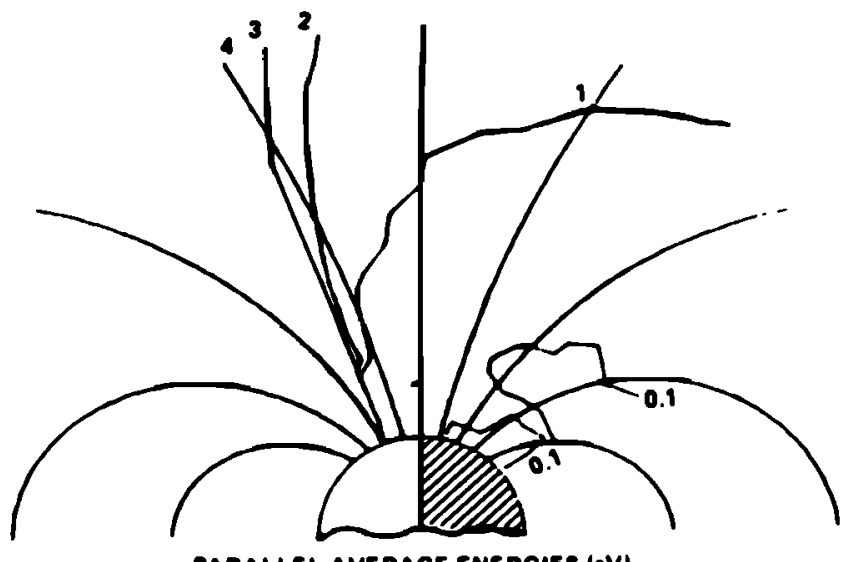

parallel avepace ene roies (ov)

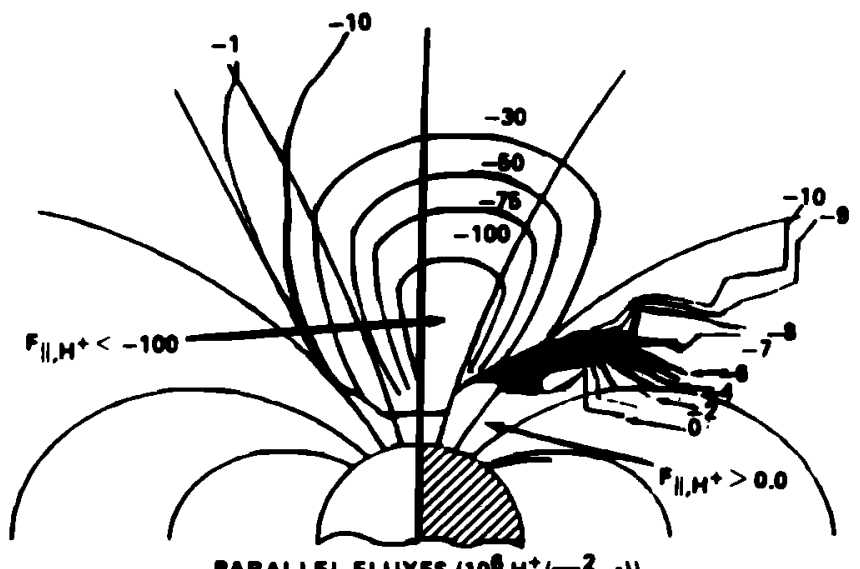

PaAallel fluXes $\left(10^{6} \mathrm{H}^{+} / \mathrm{cm}^{2}\right.$. 1 $\left.)\right)$
SOUACE.

$R_{1}=1.4 R_{\text {. }}$

$\lambda=70^{\circ}$ (DAY)

$-0^{\circ}$ (NIGHT)

$n_{1}=1000 H^{+} / C C$

$k T_{1}=0.6 \bullet V$

$k T_{118}=1,0 \mathrm{~V}$

$E_{1, p o l e}-60 \mathrm{mV} / \mathrm{m}$

$E_{\|, 1}=1 \mu \mathrm{V} / \mathrm{m}$
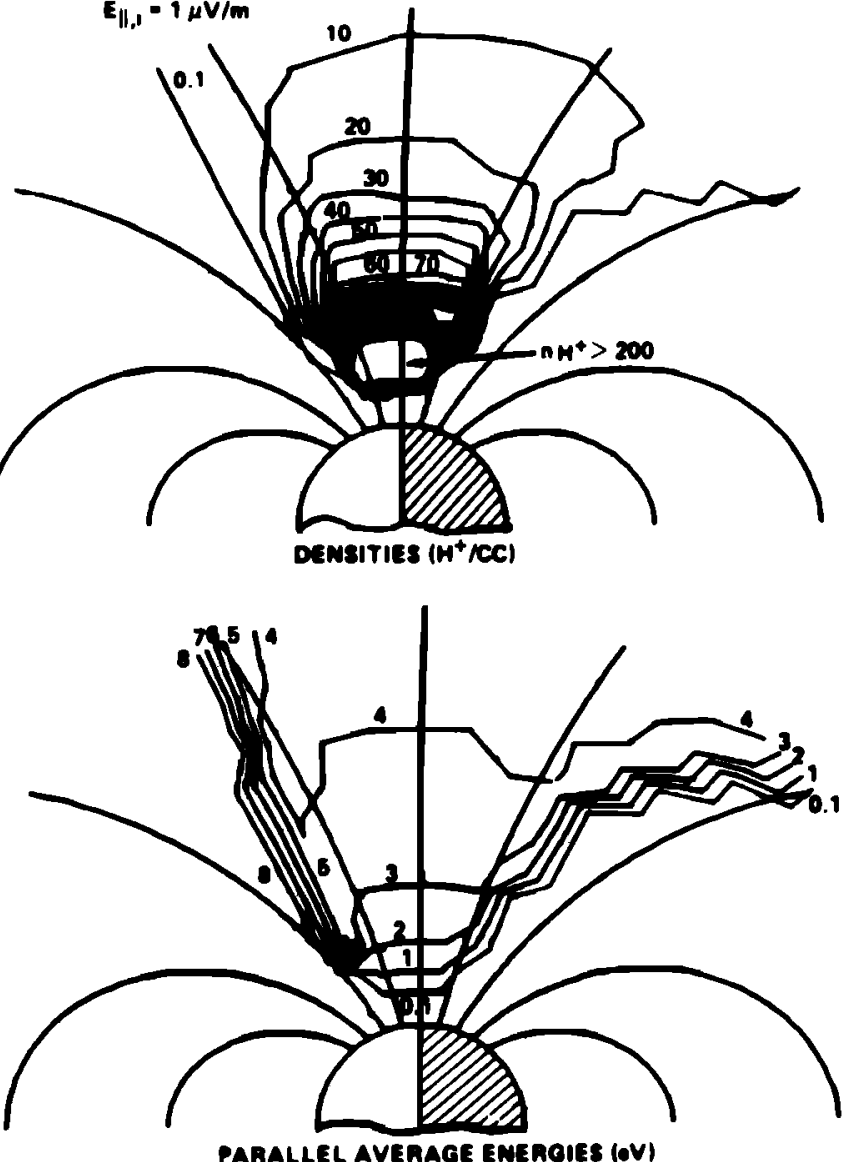

parallel average eneroies (ov)

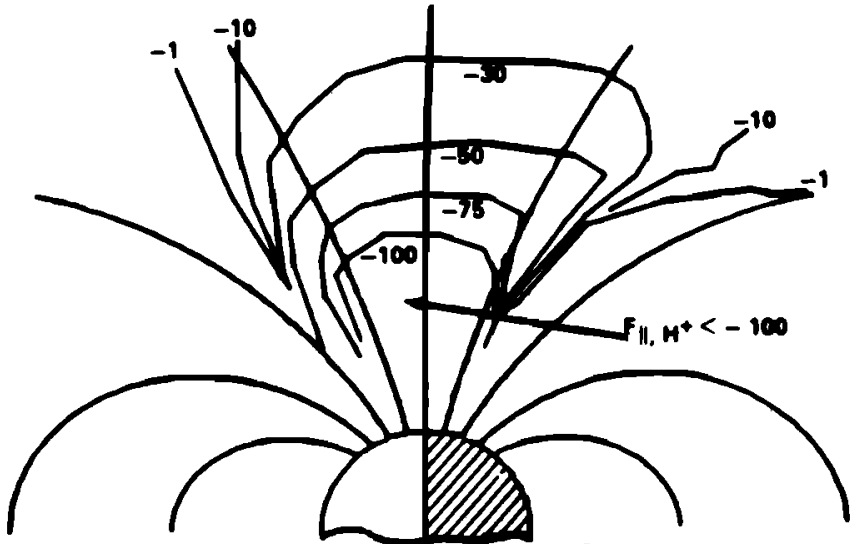

PARALLEL FLUXES $\left(10 \mathrm{H}^{+} /\left(\mathrm{cm}^{2}-\mathrm{m}\right)\right)$

Fig. 8. Two cases of the bulk parameter distributions of $\mathrm{H}^{+}$for $E \|_{, i}=0.0 \mu \mathrm{V} \mathrm{m}-1$ and $E \|_{, i}=1 \mu \mathrm{V} \mathrm{m}-1$ for a very lowenergy $\mathrm{H}^{+}$sourœ broadly distributed across the polar cap ionosphere.

velocity space is occupied at this location is the natural velocity filter effect of this system. That is, for the given parameters, only ions in a small region of velocity space, around essentially a parallel velocity which is consistent with transport from the source region, can have access to this region. In other words, the velocity filter effect in conjunction with a narrow source region can lead to high Mach number distributions distant from a low Mach 
number source region (J. H. Waite, Jr. and T. E. Moore, private communication, 1984). This situation may have been in fact present in an observation by Waite et al. [1985]. These authors fitted a drifting Maxwellian to measurements at $r=4.5 R_{E}$ in the nightside polar magnetosphere and obtained supersonic $\mathrm{O}^{+}$flows with $k T \sim$ $0.2 \mathrm{eV}$ and parallel drift velocities of $11 \mathrm{~km} \mathrm{~s}^{-1}$. The discussion here does not prove that the source distribution at lower altitudes was not supersonic for this event but does indicate that it need not have been and that the distant distribution observed could have been the natural result of the aforementioned velocity filter effect.

In summary, in this report we have described a twodimensional kinetic model of a "cleft ion fountain" which appears to be the major supplier of at least heavy ions to the polar magnetosphere. As was noted earlier, the major consequences of this model are observed in the low-energy ion measurements by the DE 1 retarding ion mass spectrometer in the companion paper by Lockwood et al. [this issue] and in studies by Lockwood et al. [1985], Waite et al. [1985], and Moore et al. [1985]. It is clear both from these observations and from the accompanying modeling efforts that the polar magnetosphere is a far more interesting environment for low-energy ions than had been realized only a short time ago and that further investigations along both modeling and observational avenues should lead to results of significant importance in the near future.

Acknowledgments. The suggestion of the velocity filter effect leading to high-altitude supersonic ion flows is attributed to $\mathbf{J} . \mathbf{H}$ Waite, Jr. and T. E. Moore. This research was supported in part by NASA contract NAS8-33982 at The University of Alabama in Huntsville. Support for M. Lockwood came from the National Research Council under the Resident Research Associate program, We would like to thank the Space Physics Analysis Network for use of the computing and networking facilities.

The Editor thanks J. Burch and N. Singh for their assistance in evaluating this paper.

\section{REFERENCES}

Balsiger, H., P. Eberhardt, J. Geiss, and D. T. Young, Magnetic storm injection of $0.9-16 \mathrm{keV} / \mathrm{e}$ solar and terrestrial ions into the high-altitude magnetosphere, $J$. Geophys. Res., 85, 1645, 1980.

Barakat, A. R., and R. W. Schunk, $\mathrm{O}^{+}$ions in the polar wind, $J$. Geophys. Res., 88, 7887, 1983.

Burke, W. J., M. C. Kelley, R. C. Sagalyn, M. Smiddy, and S. T. Lai, Polar cap electric field with northward IMF, Geophys. Res. Lett., 6, 21, 1979.

Collin, H. L., R. D. Sharp, E. G. Shelley, and R. G. Johnson, Some general characteristics of upflowing ion beams over the auroral zone and their relationship to auroral electrons, J. Geophys. Res., 86, 6820, 1981.

Craven, P. D., R. C. Olsen, C. R. Chappell, and L. Kakani, Observations of molecular ions in the earth's magnetosphere, J. Geophys. Res., in press, 1985.

Gallagher, D. L., J. D. Menietti, A. M. Persoon, J. H. Waite, Jr., and C. R. Chappell, Evidence of high densities and ion outflows in the polar cap during the recovery phase (abstract), Eos Trans. $A G U, 65,256,1984$.

Ghielmetti, A. G., R. G. Johnson, R. D. Sharp, and E. G. Shelley, The latitudinal, diurnal, and altitudinal distribution of upward flowing energetic ions of ionospheric origin, Geophys. Res. Lett., 5, 19, 1978.

Gorney, D. J., A. Clarke, D. Croley, J. Fennell, J. Luhmann, and P. Mizera, The distribution of ion beams and conics below 8000 $\mathrm{km}, J$. Geophys. Res., 86, 83, 1981.

Green, J. L., and J. H. Waite, Jr., On the origin of polar ion streams - Reply to comment by Gurgiolo and Burch, "Composition of the polar wind-Not just $\mathrm{H}^{+}$and $\mathrm{He}^{+}, "$ Geophys. Res. Lett., $12,149,1985$.

Gurgiolo, C., and J. L. Burch, DE-1 observations of the polar windA heated and an unheated component, Geophys. Res. Lett., 9, $945,1982$.

Hoffman, J. H., and W. H. Dodson, Light ion concentrations and fluxes in the polar regions during magnetically quiet times, J. Geophys. Res., 85, 626, 1980.

Horwitz, J. L., The ionosphere as a source for magnetospheric ions, Rev. Geophys., 20, 929, 1982.

Horwitz, J. L., Features of ion trajectories in the polar magnetosphere, Geophys. Res. Lett., 11, 1111, 1984.

Horwitz, J. L., and S.-I. Akasofu, On the relationship of the polar cap current system to the north-south component of the interplanetary magnetic field, J. Geophys. Res., 84, 2567, 1979.

Horwitz, J. L., C. R. Baugher, C. R. Chappell, E. G. Shelley, and D. T. Young, Conical pitch angle distributions of very low energy ion fluxes observed by ISEE $1, J$. Geophys. Res., 87, 2311, 1982.

Horwitz, J. L., R. H. Comfort, and C. R. Chappell, Thermal ion composition measurements of the formation of the outer plasmasphere and double plasmapause during storm recovery phase, Geophys. Res. Lett., 11, 701, 1984.

Lennartson, W., E. G. Shelley, R. D. Sharp, R. G. Johnson, and H. Balsiger, Some initial ISEE-1 results on the ring current composition and dynamics during the magnetic storm of December, 1977, Geophys. Res. Lett., 6, 483, 1979.

Lennartson, W., R. D. Sharp, E. G. Shelley, R. G. Johnson, and H. Balsiger, Ion composition and energy distribution during 10 magnetic storms, J. Geophys. Res., 86, 4628, 1981.

Lockwood, M., Thermal ion flows in the topside auroral ionsophere and the effects of low-altitude, transverse acceleration, Planet. Space Sci, 30, 595, 1982.

Lockwood, M., and J. E. Titheridge, Ionospheric origin of magnetospheric $\mathrm{O}^{+}$ions, Geophys, Res, Lett., 8, 381, 1981.

Lockwood, M., J. H. Waite, Jr., T. E. Moore, J. F. E. Johnson, and C. R. Chappell, A new source of suprathermal $\mathrm{O}^{+}$ions near the dayside polar cap boundary, J. Geophys. Res., 90, 4099, 1985.

Lockwood, M., M. O. Chandler, J. L. Horwitz, J. H. Waite, Jr., T. E. Moore, and C. R. Chappell, The cleft ion fountain, J. Geophys. Res., this issue.

Luhmann, J. G., and L. M. Friesen, A simple model of the magnetosphere, J. Geophys. Res., 84, 4405, 1979.

Lundin, R., L. Lyons, and N. Pissarenko, Observations of the ring current composition at $L<4$, Geophys. Res. Lett., 7, 425, 1980.

Lundin, R., B. Hultqvist, E. Dubinin, N. Pissarenko, and A. Zackarov, The plasma mantle: Composition and the characteristics observed by means of the Prognoz 7 satellite, Space Sci. Rev., $31,267,1982$.

Maezawa, K., Magnetospheric convection induced by the positive and negative $Z$ components of the interplanetary magnetic field: Quantitative analysis using polar cap magnetic records, $J$. Geophys. Res., 81, 2289, 1976.

Moore, T. E., J. H. Waite, Jr., M. Lockwood, M. O. Chandler, C. R. Chappell, M. Sugiura, D. R. Weimer, and W. K. Peterson, Upwelling $\mathrm{O}^{+}$ions: $\mathrm{A}$ case study (abstract), Eos Trans. $A G U$, $65,1056,1984$

Moore, T. E., C. R. Chappell, M. Lockwood, and J. H. Waite, Jr., Superthermal ion signatures of auroral acceleration processes, J. Geophys. Res., 90, 1611, 1985.

Nagai, T., J. F. E. Johnson, and C. R. Chappell, Low-energy $<100$ $\mathrm{eV}$ ) ion pitch angle distributions in the mangetosphere by ISEE 1, J. Geophys. Res., 88, 6944, 1983.

Nagai, T., J. W. Waite, Jr., J. L. Green, C. R. Chappell, R. C. Olsen, and R. H. Comfort, First measurements of supersonic polar wind in the polar magnetosphere, Geophys. Res. Lett., 11, 669, 1984.

Peterson, W. K., Ion injection and acceleration in the polar cusp, in The Polar Cusp, edited by J. A. Holtet and A. Egeland, pp. 67-84, D. Reidel, Dordrecht, 1985.

Peterson, W. K., R. D. Sharp, E. G. Shelley, and R. G. Johnson, Energetic ion composition of the plasma sheet, $J$. Geophys. Res., 86, 761, 1981. 
Pilipp, W. G., and G. Morfill, The formation of the plasma sheet resulting from plasma mantle dynamics, J. Geophys. Res., 83, $5670,1978$.

Sharp, R. D., D. L. Carr, W. K. Peterson, and E. G. Shelley, Ion streams in the magnetotail, J. Geophys. Res., 86, 4639, 1981.

Shelley, E. G., W. K. Peterson, A. G. Ghielmetti, and J. Geiss, The polar ionosphere as a source of energetic magnetospheric plasma, Geophys. Res. Lett., 9, 941, 1982.

Waite, J. H., Jr., T. Nagai, J. F. E. Johnson, C. R. Chappell, J. I Burch, T. L. Killeen, P. B. Hays, G. R. Carignan, W. K. Peterson, and E. G. Shelley, Escape of suprathermal $\mathrm{O}^{+}$ions in the polar cap, J. Geophys. Res., 90, 1619, 1985.

Winningham, J. D., and C. Gurgiolo, DE-2 photoelectron measurements consistent with a large scale parallel electric field over the polar cap, Geophys. Res. Lett., 9, 977, 1982.
Yau, A. W., B. A. Whalen, W. K. Peterson, and E. G. Shelley, Distribution of upflowing ionospheric ions in the high-altitude polar cap and aurotal ionosphere, J. Geophys. Res., 89, 5507, 1984.

J. L. Horwitz, Department of Physics, The University of Alabama in Huntsville, Huntsville, AL 35899.

M. Lockwood, Space Science Laboratory, NASA Marshall Space Flight Center, Huntsville, AL 35812.

(Received January 18, 1985; revised April 8, 1985;

accepted April 23, 1985.) 